\title{
Dünya ve Türkiye'de gıda israfı ve kaybına genel bir bakış
}

\author{
İsmail Hakkı Tekiner ${ }^{\mathrm{a}, \mathrm{b}, \mathrm{c} 1, *}$, Nesli Nur Mercan ${ }^{\mathrm{b} 2}$, Ayşegül Kahraman ${ }^{\mathrm{c}}$, Mervenur Özel ${ }^{\mathrm{a} 4}$ \\ a İstanbul Sabahattin Zaim Üniversitesi, Sağlık Bilimleri Fakültesi, Beslenme ve Diyetetik Bölümü, Istanbul, Türkiye

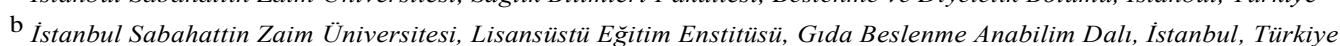 \\ c İstanbul Sabahattin Zaim Üniversitesi, Lisansüstü Eğitim Enstitüsü, Gıda Mühendisliği Anabilim Dalı, İstanbul, Türkiye
}

İstanbul Sabahattin Zaim Üniversitesi Fen Bilimleri Enstitüsü Dergisi (2021) 3 (2): 123-128

https://doi.org/10.47769/izufbed.884219

(iD) ORCID ${ }^{1}$ 0000-0002-7248-2446; ${ }^{2} 0000-0002-9348-7457 ;{ }^{3} 0000-0002-8897-6184 ;{ }^{4} 0000-0002-4124-8243$

\begin{tabular}{l}
\hline YAYIN BİLGİSI \\
\hline Yayın geçmişi: \\
Gönderilen tarih: 04 Mart 2021 \\
Kabul tarihi:10 Mart 2021 \\
\hline Anahtar kelimeler: \\
Gıda israfı \\
Gıda kaybı \\
Dünya \\
Türkiye
\end{tabular}

\section{ÖZET}

Gıda ve Tarım Örgütü (FAO), dünyada üretilen toplam gıda miktarının \%25-33’ünün israf edildiğini ve ekonomik değerinin toplam 990 milyar dolara karşllık geldiğini bildirmektedir. Türkiye İsraf Raporu 2018 yılı verilerine göre, ülkemizde her yıl 26 milyon ton gıda israf olmakta, maddi karşılığı 555 milyar TL'nı geçmekte ve milli gelirinin \%15'ine karşılık gelmektedir. Gıda israfi ve kaybı yalnızca gıda maddelerinin kaybedilmesi değil, aynı zamanda su, enerji, zaman, öz kaynakların israfı anlamına da gelmektedir. Gıda israfının gerçek boyutlarını öngörmek için kullanılan yaklaşımların tutarsız veriler vermesi ve çözüm yöntemlerinin geliştirilememesi gıda israfı arttırmaktadır. Bu çalışmada, Dünyada ve Türkiye'de gıda israfı ve kaybının durumunu ele almak amaçlanmıştır.

\section{A general view to food waste and loss in the world and Turkey}

\begin{tabular}{l}
\hline ARTICLE INFO \\
\hline Article history: \\
Received: 04 March 2021 \\
Accepted: 10 March 2021 \\
\hline Key words: \\
Food waste \\
Food loss \\
World \\
Turkey
\end{tabular}

ABSTRACT
The Food and Agriculture Organization (FAO) reports that $\% 25-33$ of the total amount of food
produced in the world is wasted and its economic value corresponds to 990 billion dollars.
According to the data from Turkey's Waste Report for 2018, 26 million tons of food is wasted a
year in our country, its monetary equivalent exceeds 555 billion $€$, and corresponds to $\% 15$ of the
national income. Food waste and loss means not only the loss of foodstuffs, but also a waste of
water, energy, time and own resources. The approaches used to predict the true extent of food
waste have given inconsistent data, and underdeveloped solution methods also increases food
waste. In this study, we aimed to review the status of food waste and loss in the world and Turkey.

\section{Giriş}

Gıda israfı, dünya genelinde acil önlem alınması gereken konular arasına girmiştir. BM Gıda ve Tarım Örgütü (FAO), dünyada her yıl üretilen toplam gıda miktarının 1/3'ünün (1.3 milyar ton) israf edildiğini ve ekonomik değerinin 990 milyar dolara karş11ık geldiğini bildirmektedir (FAO, 2019).

Dünya genelinde gıda israfının \%30'unu tahıllar (dünya yıllık tahıl üretiminin yarıs1), \%40-50'sini köklü bitkiler, meyveler ve sebzeler, \%20'sini yağlı tohumlar, et ve süt ürünleri ile balık çeşitleri oluşturmaktadır. Avrupa ve Kuzey Amerika'da kişi başı yıllık gıda atık miktarı 95-115 kg arasında değişirken,
Afrika, Güney ve Güney doğu Asya ülkelerinde 6-11 kg olarak tahmin edilmektedir. Gelişmekte olan ülkelerde gıda israfının \%40'1 hasat öncesi, hasat ve işleme esnasında gerçekleşirken, gelişmiş ülkelerde ise perakende satış zincirleri ve tüketim sırasında oluşmaktadır (Sputnik, 2019; İSRAF, 2019).

Türkiye İsraf Raporuna göre, ülkemizde her yıl 26 milyon ton gida israf olmaktadır. Bu miktar milli gelirin \%15'ine denk gelmekte ve maddi karşılığı 555 milyar TL'nı bulmaktadır. İsraf edilen gıda yalnızca gıda maddelerinin çöpe gitmesi demek değildir. Aynı zamanda doğal kaynakların da kaybı anlamına gelmektedir. Teorik olarak israf edilen gidaların 
\%60'ının geri kazanılabileceği ya da tekrar değerlendirilebileceği düşünüldüğünde, durumun ciddiyeti daha iyi anlaşılmaktadır. Gıda israfı doğal kaynakları, ekonomiyi, tarımı, toprak verimliliğini, çevre ve doğal dengeyi, sağlığ1, küresel ısınma ve iklimi, uluslararası ilişkileri ve politikaları, gelişme çabalarını, sosyal eşitlik ve gelir dağılımını ve diğer pek çok alanı ciddi şekilde etkileyen karmaşık bir konudur (T.C. Ticaret Bakanlığı, 2018; TİSVA, 2019).

Bu çalışmada, Dünyada ve Türkiye'de gıda israfı ve kaybının durumu ve ele alınması amaçlanmıştır.

\section{Dünyada Gıda İsrafı ve Kaybı}

Dünyada nüfus artış hızına bağlı olarak gıda israfı da artmakta, çevre kirliliği, sağlık riski ve boş alanların azalması gibi diğer çevresel sorunlara uygun ortamı oluşturmaktadır. FAO, dünyada her yıl 990 milyar dolar değerinde 1.3 milyar ton gidanın israf edildiğini bildirmektedir (FAO, 2019).

Dünyada israf edilen gıda maddeleri arasında ilk sırayı meyve ve sebzeler (\%44) almaktadır. Bunu kök ve yumrulu bitkiler (\%20) ile tahı (\%19) grupları izlemektedir. Gıda tedarik zincirinde ise israfın en çok görüldügü basamaklar, tüketim (\%35), üretim (\%24), toplama ve depolama (\%24) ve dağıtım (\%5) olarak belirlenmiştir (Gönültaş vd., 2020).

Gıda zinciri kayıpları ülkelere göre değişiklik göstermektedir. Örneğin, Avustralya ve Yeni Zelanda'da \%5-6's1, Orta ve Güneydoğu Asya'da \%20-21'i ve Avrupa ve Kuzey Amerika'da ise \%16's1 atılmakta ya da kaybolmaktadır. Hanehalkı tarafından israf edilen gıda miktarı, ABD'de 40 milyon ton, AB'de 47 milyon ton, İngiltere'de 4.5 milyon ton, Avustralya'da 7.3 milyon ton ve Çin'de ise 18 milyon ton 'dur. $\mathrm{Bu}$ nedenle, BM gida israfi ile mücadeleyi 17 sürdürülebilir kalkınma hedefi arasına almıştır. FAO ve BM Çevre Teşkilatı, gıda israfı ve kaybını; Gıda Kaybı İndeksi (FLI) ve Gıda İsrafi İndeksi (FWI) olarak iki ayrı parametre ile izlemektedir. FLI, FAO'nun 2019 y1lı raporunda yer alırken, FWI üzerinde ise çalışmalar devam etmektedir (IFCO, 2020).

Küresel gıda kaybı tahmini ilk kez 2019 yılında FAO tarafından yayımlanmıştır. Verilere göre, üretilen gıdanın $\% 13.8$ 'i tarımsal süreçlerde israf edilmekte veya kaybolmaktadır. Gıda israfı ve kaybına ilişskin nedenlerin belirlenmesini amaçlayan bu çalışma ile kaybın en aza indirilmesine dönük öncelikli eylemlerin belirlenmesi amaçlanmıştır. Ayrıca, bu çalışma, gıda zincirinin tüm aşamalarında gıda kaybının ve israfının birbirine yakın oranlarda olduğunu; bunun başlica nedeninin ise süreçlerin birbirleri üzerindeki zincirleme etkilerine dayandığını göstermiştir (FAO, 2020).

Gıda Güvenliği ve Beslenme Uzmanlar Paneli (HLPE), gıda zinciri kayıplarını birbirleri ile olan ilişkileri bakımından: (1) mikro (iç ve dış nedenlere bağlı olmaksızın her koşulda gerçekleşen), (2) mezo (mikro düzeyde ortaya çıkan gıda kayıplarının oluşumunda rol oynayan ve ikincil sebeplerden meydana gelen) ve (3) makro (mezo ve mikro düzeylerdeki israflar dâhil olmak üzere diğer nedenler) olmak üzere üçe ayırmıştır. Gıda işleme süreçlerinin mezo düzeyde gıda kaybına yol açtığı görülmektedir (HLPE, 2014).

\section{1 Çin}

Çin, dünyanın en hızlı gelişen ekonomilerinden birisi olması sebebiyle güçlü bir talep merkezi olmuştur. Gün geçtikçe artan nüfusu ve hızlı kentleşme Çin toplumunun daha farklı yaşam ve beslenme tarzını benimsemesine yol açmaktadır. $\mathrm{Bu}$ bakımdan küresel gıda piyasalarının ve gıda-tarım sistemlerinin yeniden şekillendirilmesinde önemli bir çarpan etkisine sahiptir. Küresel gida güvencesi endeksine göre Çin'in puanı 65.5 olup, 113 ülke arasında 42. Sırada yer almaktadır (Gökten ve Gökten, 2017). Çin'in ekilebilir alanlarının 26 milyon hektarı israf edilmektedir. Bu bakımdan gıda israfı ve kaybına yönelik stratejisini işlenmemiş tarım ürünleri ithalatçısı ve işlenmiş ürün ihracatçısı olma şeklinde belirlediği görülmektedir (Song vd., 2018). Çin'de israf edilen gıdanın su ürünleri yetiştiriciliğinde yem katkısı olarak değerlendirildiği bilinmektedir (Mo vd., 2018). Çin gida tüketici boyutunda gıda israfinı ile mücadelede ise 4. sırada yer almaktadır (Sarıkaya vd., 2020).

\subsection{Amerika Birleşik Devletleri}

Dünyada açlık sınırında yaşayan kişi sayısının 821 milyon olarak bildirilmektedir (FAO, 2018). Bu etkinin günümüze kadar katlanarak varmasının en büyük nedenlerinden biri ise gıda israfıdır (Durna, 2020). Amerika Birleşik Devletleri (ABD) hane halkının satın aldıkları gıdaların \%25'ini çöpe attıkları rapor edilmektedir. $\mathrm{Bu}$ israf rakamı ayrıca içme suyunun $\% 25$ 'inden fazlasina ve 300 milyon varil petrolün kaybına denk gelmektedir. ABD'de yapılan bir diğer araştırmaya göre, hasat sırasında gıda kaybı oranı \%31'dir. Gıda kaybının üçte birinin marketler ve perakende satış zincirinde (165.5 milyar dolar) olduğu bilinmektedir (Ceryes vd., 2021). ABD'de gıda israfı ve kaybını önlemeye yönelik stratejiler bağlamında, politika değişiklikleri, eğitim ve bilinçlendirme gibi faaliyetlere ağırlık verilmektedir (Huang vd., 2020).

\subsection{Avrupa Birliği}

Avrupa Birliği (AB)'nde 79 milyon insan yoksulluk sınırı altında yaşamakta olup, 16 milyonunun gıda yardımına ihtiyaç duyduğu bilinmektedir. Diğer taraftan ise, AB'de her y1l 89 milyon ton gıdanın çöpe atıldığı rapor edilmektedir. İsraf miktarının ise 2020 yılı sonunda 120 milyon tona ulaşacağı öngörülmektedir. Birlik ülkelerinde gıda israfı ve kaybı sorununun başlıca sebeplerinden birisi olarak ekonomik gelişme gösterilmektedir (EESC, 2014; Castillo-Giménez vd., 2019). AB hakkındaki veriler gıda israfi ile mücadele için yeni stratejilerin geliştirilmesi gerekliliğini göstermektedir (Corrado, 2018). Bu bağlamda, AB, bilgi ağları ile halkı bilinçlendirme kampanyaları yapmakta, gıdaya uygulanan desteklemelerin azaltılmasına ve gıda yönetmeliklerinde değişikliklere gitmekte ve israfını önlemek için ekonomik teşvikler vermektedir (Priefer vd., 2016). Avrupa Parlamentosu gıda israfının 2025 yılında yarıya indirilmesi için önlemler alınması yönünde karar almış ve 2014 yılını "Avrupa Gıda İsrafına Karşı Eylem Yı1ı" olarak ilan etmiştir (Demirbaş, 2018). Aynı zamanda, Avrupa Atık Yönetmeliği'nde değişiklikler yapılmış ve üye devletlerin g1da israfını 2025 yılına kadar $\% 30$ azaltmaları talep edilmiştir.

\subsection{Finlandiya}

Finlandiya'da hane halkı tarafından yıllık israf edilen gida miktarı 100 bin taşıtın atmosfere saldığı karbondioksit (CO2) salınımına eşittir. İsrafın maddi karşılığı ise 550 milyon Euro/yıl olup, israf kaynakları ise ev, restoran, gıda endüstrisi 
ve perakende sektörüdür (Katajajuuri vd., 2014).Barilla Gıda ve Beslenme Vakfi (BCFN) ve The Economist Intelligence Unit (EIU) tarafından yapılan bir araştırma, Finlandiya'nın FSI notuna göre dünyada ilk beş ülke içinde olduğunu göstermiştir (Gönültaş vd., 2020). Bu bağlamda, Finlandiya'da da gıda israfı ile mücadeleye dönük faaliyetlere ve toplumsal projelere ("Less Food Wasted Means More Money in Your Wallet”) ağırlık verildiği görülmektedir (Silvennoinen vd., 2019).

\subsection{Güney Afrika Cumhuriyeti}

Güney Afrika Cumhuriyeti'nde gıda israfı ve kaybının başlıca kaynakları; evsel, meyve-sebze ve et işleme ve dağıtım süreçleri olup, tüm gıda tedarik zincirindeki toplam israf 7.7 milyar doları bulmaktadır (Termeer vd., 2018; Adenuga vd., 2020).

\subsection{Japonya}

Japonya'nın gıda israfı ve kaybı eğilimini tespit etmek için kullandığı teknik "kalori/protein tedarik ve alımı arasındaki eşitsizliği belirleme" yaklaşımıdır. Bu kapsamda, 1960 ve 2012 yılları arasını üç döneme ayıran Japonya gıda tedarik zincirinde tüm kritik kontrol noktalarını değerlendirmeye almıştır. Çalışma sonucu, 1960-1975 arası gıda israfı ve kaybı düşük seviyelerde iken, 1975-2000 döneminde artışa geçmiş ve 2001 yılından başlayarak yeniden düşüş eğilimi göstermiştir. Japonya, 2011 yılı itibariyle gıda atıklarının \%43'ü geri dönüştürmeyi başarabilmiş bir ülkedir (Liu vd., 2016).

\subsection{Diğer ülkeler}

Araştırmalar, gıda kaybı ve israfının \%56'sının gelişmiş ülkelerde olduğunu göstermektedir (FAO, 2011). Yeni Zelanda'da gida kaybı yıllık 872 milyon dolar, Kanada'da 26.6 milyar dolar ve İngiltere'de ise 15 milyar £ olarak tahmin edilmektedir (Reynolds vd., 2016). Dünyanın diğer coğrafyalarından Sahra Altı Afrika ve Güney/Güneydoğu Asya'da kişi başı israf 120-170 kg/yıl ve Avrupa ve Kuzey Amerika'da 95-115 kg/yıl 'dır (Demirbaş, 2018). İngiltere'de Leeds Üniversitesi'nin gıda israfi ile mücadele konulu en çok çalışma yapan kurum olduğu bilinmektedir (Sarıkaya vd., 2020).

\section{Gıda İsrafi ve Kaybı İle Mücadele}

Gıda israfı ve kaybını azaltıcı çalışmaların iklim değişikliği, enerji kullanımı, gıda ve su güvenliği ile arazi kullanımı gibi faaliyetler üzerinde olumlu sonuçları olmaktadır (Lipinski vd., 2013). Günümüzde doğanın ve ekosistemlerin insan eliyle tahribatı kaynaklı çevresel sorunlar artmaktadır. Bu nedenle, çeşitli ülkelerde gıda israfı kaynaklı çevre sorunları ile mücadele için bazı projeler uygulanmıştır. Ancak, katılımının az olması sebebiyle beklenen sonuçlar elde edilememiştir (Evans vd., 2012; Van der Werf ve Gilliland, 2017).

Hükümetler ve sivil toplum örgütlerinin gıda israfı ve kaybına dönük yayımladıkları raporlar sayesinde durumun ciddiyeti daha kapsamlı görülebilmektedir. Örneğin, dünyada bu konuda yayımlanan bilimsel yayınlar 2011-2015 döneminde \%70 artış göstermiştir (Xue vd., 2017). Bu gibi araştırmaların özellikle Kuzey Amerika, Kuzey ve Batı Avrupa gibi gelişmiş ülkelerin olduğu bölgelere daha fazla olduğu görülmekte; diğer taraftan Hindistan gibi bazı ülkelerin ise detaylı incelenmediği dikkat çekmektedir (Silvennoinen vd., 2015).
Gida tedarik zincirinde israf ve kaybının nedenlerini belirlemeye dönük çalışmalar artarak sürmektedir. İlk sonuçlar, demografik ve psikolojik faktörler, bilinçli olmama, düşük motivasyon, eksik tanımlamalar, uygun olmayan saklama koşulları ve yanlış satın alma alışkanlıklarının öne çıktığını göstermektedir (Visschers vd., 2016). Perakende gıda hizmetlerindeki gıda israfi ve kaybının çevresel etkileri bulunmaktadır. Ekmek, sebze, meyve, hamur işi, et ve et ürünleri, süt ve süt ürünleri, hazır yemekler ve diğer ürünler perakende zincirinde en çok israf edilen gıda gruplarıdır. Bu sebeple, bahsedilen ürünlerde israf ve kaybı azaltacak tedbirlerin çevresel olumsuz etkileri düşüreceği anlaşılmaktadır. Gıda israfı ve kaybında perakende dışında evsel tüketim alışkanlıklarının israf edilen gıdaların \%35'ini oluşturduğu bilinmektedir. Bu durum gelişmiş ve gelişmekte olan ülkeler arasında ise ciddi farklılıklar göstermektedir. Eş zamanlı olarak 44 ülkede yürütülen bir araştırma ise mevzuatlar ve ekonomik teşviklerin evsel gıda atık miktarını olumlu yönde azalttığına işaret etmektedir (Chalak vd., 2016). Konaklama işletmelerinin de gida israfina olumsuz katkısı olduğunu ve bu tür kuruluşların da alacakları tedbirler sayesinde gıda israfını \%57'ye varan oranda düşürebilecekleri gösterilmiştir. Benzer şekilde, okullarda sağlıklı beslenme anlayışının geliştirilmesi ile sebze ve meyve israfı \%28'e kadar düşürülebilmiştir. Aynı zamanda, kamuoyunu bilinçlendirecek kampanyaların gıda israfını \%28'e kadar azaltabildiği ortaya konulmuştur (Reynolds vd., 2019).

\section{Türkiye'de Gıda İsrafı ve Kaybı}

Türkiye'de yıllık israf edilen gıdan miktarı 26 milyon tondur. En fazla israf meyve ve sebze grubunda gerçekleşmekte olup, üretilen miktarın \%25-40'1 kaybedilmektedir. Ayrıca, ekmek ülkemizde katı atık miktarının yıl geçtikçe artmasının en büyük nedenleri arasında gelmektedir. Türkiye'de günlük 4.9 milyon adet (yıllık olarak 1,7 milyar adet) ekmek israf edilmektedir (Şahin vd., 2018). Bu rakamın 3 milyonu firınlarda (\%62), 1.4 milyonu evlerde (\%28), 0.5 milyonu personel ve öğrenci yemekhaneleri ile lokanta ve otellerde (\% 10) gerçekleşmektedir. Bayat ekmeklerin akıbetini belirlemek için yapılan bir araştırmaya göre, \%71'i yemek-tatlı yapılarak, \%49'u sokak hayvanlarına ve evcil hayvan sahiplerine verilerek ve \%14'ü ise derin dondurucuda saklanmaya alınarak değerlendirilmektedir. Çalışmaya katılan kişilerin sadece \%11'i ekmeği direkt çöpe attıklarını ifade etmiştir (Türkiye İsraf Raporu, 2018).

Türkiye'de gıda israfina dönük çalışmalar en çok kayıp ve israfın erken üretim sonrası aşamasından orta seviyelere kadar olan süreçlerde yaşandığını göstermektedir. Gıdaların maksimum \%5'inin tüketim ve hane halkı (son tüketici) tarafından israf edildiğini ortaya koymaktadır (Tatlıdil vd., 2013). Türkiye yüksek-orta gelir seviyesi ülkeler grubunda olmakla birlikte, Küresel Gıda Güvenliği Endeksi (GFSI)'ne göre Orta Doğu ve Kuzey Afrika ülkeleri kategorisinde değerlendirilmektedir. Buna göre, Türkiye'nin gıda güvencesi puanı iyi durumuna işaret eden 63.9 iken, son BM raporuna göre, kişi başı yıllık gıda israfında ise Demokratik Kongo Cumhuriyeti ve Meksika'nın arkasından $92.3 \mathrm{~kg}$ ile dünya üçüncülüğünü almaktadır (Dağdur ve Olhan, 2015; BM 2021). Ülkemizde gıda israfına dönük faaliyetlerin ekmek gibi bazı ürünlerde yoğunlaştı̆̆ı, diğer taraftan diğer gıda gruplarının yeterince ilgi görmedikleri fark edilmektedir (Demirbaş, 2018). 
İstanbul, Ankara, İzmir, Antalya, Muğla, Denizli ve Gaziantep illerinde yerleşik beş yıldızlı otel işletmelerinde gerçekleştirilen bir araştırmaya göre, günlük gıda israfı miktarı yaklaşı 6 ton $\mathrm{kg}$ olup, tüm atık toplamının \%70'ine karşılık gelmektedir. Konaklama işletmelerinde gida israfi ve kaybının en çok meydana geldiği birimler: mutfak, servis ve bar hizmetleridir. Ayrıca, porsiyon miktarını fazlalığı, müşterilerin tüketebileceklerinden fazla yiyecek-içecek almaları, kalitesiz ürün kullanımı, personelin eğitimsizliği, pişirme ve saklama eksikleri, depolama sorunları ve bilinçsiz satınalma gibi faktörler israf miktarını olumsuz yönde etkileyen diğer faktörlerdir (EPA, 2010; Şahin ve Bekâr, 2018).

Toplu beslenmede (Catering) işletmelerinde kişi başı günlük 38-50 g ekmeğin israf edildiği bilinmektedir (Kaya ve İlhan, 2018).

Yaş meyve ve sebzede genel anlamda kayıplar, hasat esnasında \%4-12, ürünlerin pazara veya hale taşınmasında $\% 2-8$, pazara hazırlık sırasında $\% 5-15$, depolama sürecinde \%3-10 ve tüketim esnasında \%1-5 olmak üzere toplamda $\% 15-50$ arasındadır. $\mathrm{Bu}$ kayıpların sebebi ise, üretim sırasındaki yanlış uygulamalar ve sonucunda meydana gelen çürümeler, nakliye sırasında oluşan kayıplar, ön soğutmanın uygun yapılamamas1, uygun muhafaza ve ambalajlamanın eksik olması ve işçilik hatasıdır (Ünlü, 2015).

Gıda israfı ve kaybının en yüksek görüldüğü taze meyve sebze ürünlerinde üretim, hasat ve hasat sonrası meydana gelen kayıpların azaltılması için İyi Üretim Uygulamaları (GMP), etkin yönergeler ve üreticinin bilinçlendirilmesinin önemine dikkat çekilmektedir. Örneğin, Antalya ili sebze-meyve komisyonculara göre fire sebepleri arasında ilk sırayı \%29 ile ürünün bekleme süresi almaktadır. Bunu \%18 ile işçi hatası ve taşıma sırasında oluşan kayıplar takip etmektedir. Ayrıca, fire, ürünlerin \%32'si hasat ve taşıma esnasında gerçekleşmektedir (Tarabay vd., 2018; GTHB, 2018).

Gıda atık hiyerarşisinde öncelik gıda atığını kaynağında oluşmadan önlemek ya da daha düşük orana çekmeye çalışmaktır. Son safhada ise gıda atıklarının kullanılabilir forma (kompost vb.) dönüştürülmesi ya da bir diğer ifadeyle geri dönüşümünün yapılması gelmektedir. Ayrıca, geri dönüşümü mümkün olmayan gıda atıklarının çevreye etkilerini azaltacak biçimde depolanması ya da saklanması gereklidir (EPA, 2014).

Katı Atık Ana Planı Projesi (KAAP) kapsamında 2006 yılında yapılan katı atık kompozisyon belirleme çalışmasının sonuçlarına göre Türkiye'deki belediye atıklarının \%34'ünü mutfak atıkları oluşturmaktadır (Bilim, Sanayi ve Teknoloji Bakanlığı, 2014).

\section{Sonuç ve Öneriler}

Bu çalışmada dünya ve Türkiye'de gıda israfı ve kaybının durumu hakkında genel bilgiler paylaşılmıştır. Gıda israfı ve kayb1 insanlığ1 etkileyen çok yönlü bir küresel risk halini almıştır. Bu olumsuz durumla mücadele için yasal otoritelerin ve sivil toplum örgütlerinin harekete geçtikleri ve mücadele amaçlı uygulamaları hayata geçirdikleri görülmektedir. Gıda israfı ve kaybının göründüğünden daha karmaşı ve çok faktörlü bir olgu olduğu anlaşılmaktadır. Özellikle, ülkemizde gıda israfinın sadece tek bir değişkene bağlı olmadığı anlaşılmaktadır. Sonuç olarak, gıda israfı ve kaybı ile multidisipliner ve çok yönlü mücadeleyi geliştirecek politikalar, stratejiler ve toplumun tüm kesimlerini bilinçlendirecek uygulamalara ağırlık verilmesinin gerekliliği ve aciliyeti olduğu sonucuna varılmıştır.

\section{Kaynaklar}

Adenuga, O. T., Mpofu, K., \& Modise, K. R. (2020). An approach for enhancing optimal resource recovery from different classes of waste in South Africa: Selection of appropriate waste to energy technology. Sustainable Futures, 2, 100033.

Birleşmiş Milletler (BM). (2021). UNEP Food Waste Index Report 2021 , https://www.unep.org/resources/report/unep-foodwaste-index-report-2021 Son Erişim Tarihi: 09.03.2021

Castillo-Giménez, J., Montañés, A., \& Picazo-Tadeo, A. J. (2019). Performance and convergence in municipal waste treatment in the European Union. Waste Management, 85, 222-231.

Ceryes, C. A., Antonacci, C. C., Harvey, S. A., Spiker, M. L., Bickers, A., \& Neff, R. A. (2021). "Maybe it's still good?" A qualitative study of factors influencing food waste and application of the EPA Food Recovery Hierarchy in US Supermarkets. Appetite, 161, 105111.

Chalak, A., Abou-Daher, C., Chaaban, J., \& Abiad, M. G. (2016). The global economic and regulatory determinants of household food waste generation: A cross-country analysis. Waste management, 48, 418422.

Corrado, S., \& Sala, S. (2018). Food waste accounting along global and European food supply chains: State of the art and outlook. Waste management, 79, 120-131.

Dağdur, E., \& Olhan, E. (2015). Küresel Gida Güvencesi Endeksi Kapsamında Türkiye'nin Değerlendirilmesi. Turkish Journal of Agricultural Economics, 21(2), 4961.

Demirbaş, N. (2018). Dünyada ve Türkiye'de gıda israfını önleme çalışmalarının değerlendirilmesi. VIII. IBANESS Kongreler Serisi, Plovdiv, Bulgaristan.

Durna, D. (2020). Amerika Birleşik Devletlerinde Gıda Bankacılığı Uygulaması. Sosyal Politika Çalışmaları Dergisi, 20(47), 339-354.

EESC. (2014). Prevention and reduction of food waste, http://www.eesc.europa.eu/?i=portal.en.natopinions.25955, Son Erişim Tarihi: 09.03.2021

EPA. (2010). Less Food Waste More Profit. A Guide To Minimising Food Waste In The Catering Sector, http://www.tipperarycoco.ie/sites/default/files/Publica tions/Less\%20Food\%20Waste\%20More\%20Profit\%2 0Booklet\%202010.pdf 15.10.2015 Son E rişim Tarihi: 08.03.2021

EPA. (2014). A Guide to Conducting and Analyzing a Food Waste Assessment. https://www.epa.gov/sites/production/files/201508/do cuments/r5_fd_wste_guidebk_020615.pdf 25.09.2015 Son Erişim Tarihi: 25.09.2015

Evans, D., Campbell, H., \& Murcott, A. (2012). A brief prehistory of food waste and the social sciences. The Sociological Review, 60, 5-26. 
FAO. (2011). Global Food Losses and Food Waste-Extent, Causes and Prevention. http://www.fao.org/3/i2697e/i2697e.pdf Son Erişim Tarihi: 08.03.2021

FAO. (2019). Food and Agriculture Organization. Food waste: "'Key facts on food loss and waste you should know!'. https://twosides.info/includes/files/upload/files/UK/M yths_and_Facts_2016_Sources/1819/Key_facts_on_food_loss_and_waste_you_should know-FAO 2016.pdf Son Erişim Tarihi: 09.03.2021

FAO. (2020). Food loss and waste. ttp://www.fao.org/foodloss-and-food- waste/flw-data Son Erişim Tarihi: 09.03.2021

GTHB. (2018). Gıda Zincirindeki Hasat Sonrası Kayıpları Azaltmak için Yenilikçi Yaklaşımlar, Meyve ve Sebzelerin Depolama ve Nakliye Uygulamaları Eğitim Materyali.

Gökten, Y. S., \& Gökten, K. (2017). Neoliberal Gıda Rejimi ve Çin'de Gıda Güvencesi: Ekonomi Politik Bir Perspektif. Ömer Halisdemir Üniversitesi İktisadi ve İdari Bilimler Fakültesi Dergisi, 10(2), 11-28.

Gönültaş, H., Kızılaslan, H., \& Kızılaslan, N. (2020). Gıda İsrafının Davranışsal Belirleyicileri; Tokat İli Örneği. Gaziosmanpaşa Bilimsel Araştırma Dergisi, 9(3), 1424.

HLPE. (2014). Food losses and waste in the context of sustainable food systems. A report by the High Level Panel of Experts on Food Security and Nutrition of the Committee on World Food Security, Rome 2014.

Huang, I. Y., Manning, L., James, K. L., Grigoriadis, V., Millington, A., Wood, V., \& Ward, S. (2020). Food waste management: a review of retailers' business practices and their implications for sustainable value. Journal of Cleaner Production, 285, 125484.

IFCO. (2020). Food waste by country: who's the biggest waster? https://www.ifco.com/countries-with-theleast-and-most-food-waste/ Son Erişim Tarihi: 16.12.2020

İSRAF. (2019). 2018 Rakamları ile Türk Ekonomisinin Kara Deliği-1. http://israf.org/sayfa/2018-RAKAMLARIILE-TURK-EKONOMISININ-KARA-DELIGIISRAF-1/557 Son Erişim Tarihi: 07.03.2021

Katajajuuri, J. M., Silvennoinen, K., Hartikainen, H., Heikkilä, L., \& Reinikainen, A. (2014). Food waste in the Finnish food chain. Journal of Cleaner Production, 73, 322-329.

Kaya, S. Y., \& İlhan, S. (2018). Toplu yemek (hazır yemek) sektöründe yaşanan problemler ve çözüm önerileri. Güncel Turizm Araştırmaları Dergisi, 2(Ek1), 553-581.

Lipinski, B., Hanson, C., Waite, R., Searchinger, T., Lomax, J., \& Kitinoja, L. (2013). Reducing food loss and waste. https://www.wri.org/publication/reducingfood-loss-and-waste Son Erişim Tarihi: 09.03.2021

Liu, C., Hotta, Y., Santo, A., Hengesbaugh, M., Watabe, A., Totoki, Y.\& Bengtsson, M. (2016). Food waste in Japan: Trends, current practices and key challenges. Journal of Cleaner Production, 133, 557-564.
Mo, W. Y., Man, Y. B., \& Wong, M. H. (2018). Use of food waste, fish waste and food processing waste for China's aquaculture industry: Needs and challenge. Science of the Total Environment, 613, 635-643.

Priefer, C., Jörissen, J., \& Bräutigam, K. R. (2016). Food waste prevention in Europe-A cause-driven approach to identify the most relevant leverage points for action. Resources, Conservation and Recycling, 109, 155-165.

Reynolds, C. J., Mirosa, M. ve Clothier, B. (2016). New Zealand's food waste: estimating the tonnes, value, calories and resources wasted. Agriculture, 6(1), 9.

Sarıkaya, G. S., Bölükbaş, R., \& Erol, E. (2020). Gıda İsrafina Yönelik Çalışmaların Bibliyometrik Analizi. Journal of Tourism and Gastronomy Studies, Special Issue (4), 246-256.

Silvennoinen, K., Nisonen, S., \& Pietiläinen, O. (2019). Food waste case study and monitoring developing in Finnish food services. Waste Management, 97, 97-104.

Silvennoinen, K., Heikkilä, L., Katajajuuri, J. M., \& Reinikainen, A. (2015). Food waste volume and origin: Case studies in the Finnish food service sector. Waste management, 46, 140-145.

Song, G., Zhang, H., Duan, H., \& Xu, M. (2018). Packaging waste from food delivery in China's mega cities. Resources, Conservation and Recycling, 130, 226-227.

Sputnik. (2019). Türkiye yılda 214 milyar liralık gıda israf ediyor.

https://tr.sputniknews.com/ekonomi/20190929104027 8150-turkiye-yilda-214-milyar-liralik-gida-israfediyor/ Son Erişim Tarihi: 09.03.2021

Şahin, S. K., \& Bekar, A. (2018). Küresel Bir Sorun "Gida Atıkları": Otel İşletmelerindeki Boyutları (A Global Problem). Studies, 6(4), 1039-1061.

Tarabay, P.A., H. Chahine-Tsouvalakisb, S. T. Tawkc, N. Nemera, W. H. (2018). Reduction of Food Losses in Lebanese Apple Through Good Harvesting and Postharvest Practices, Annals of Agricultural Sciences, 63, 207-213.

Tatlıdil, F.F., Dellal, İ., \& Bayromoğlu Z. (2013). Food Losses and Waste in Turkey, FAO.

T.C. Bilim, Sanayi ve Teknoloji Bakanlığı Sanayi Genel Müdürlüğü. Ulusal Geri Dönüşüm Strateji Belgesi ve Eylem Planı 2014-2017.

T.C. Ticaret Bakanlığı, (2018). Türkiye İsraf Raporu. Tüketicinin Korunması ve Piyasa Gözetimi Genel Müdürlügü, ISBN: 978-605-5254-31-5, Ankara.

Termeer, C. J., Drimie, S., Ingram, J., Pereira, L., \& Whittingham, M. J. (2018). A diagnostic framework for food system governance arrangements: The case of South Africa. NJAS-Wageningen Journal of Life Sciences, 84, 85-93.

TİSVA, (2019). Dünyada Gıda İsrafının Karşılaştırmalı Analizi. http://israf.org/public/admin/filemanager/uploaded/kit apciklar/dunyada_gida_israf\%C4\%B1karsila Son Erişim Tarihi: 08.03.2021

Türkiye İsraf Raporu. (2018). Türkiye İsraf Raporu. http://www.consumeracademy.gov.tr/data/5aa22bf4dd 
ee7f89ac728e1d/T\%C3\%BCrkiye\%20\%C4\%B0sraf

\%20Raporu.pdf Son Erişim Tarihi: 09.03.2021

Ünlü M. (2015). Yaş Meyve ve Sebzelerde Derim (hasat) Sonrası Oluşan Kayıplar ve Çözüm Önerileri. T.C. Gıda Tarım ve Hayvancılık Bakanlığı Tarımsal Araştırmalar ve Politikalar Genel Müdürlüğü.

Van der Werf, P., \& Gilliland, J. A. (2017, May). A systematic review of food losses and food waste generation in developed countries. In Proceedings of the Institution of Civil Engineers-Waste and Resource Management, 170(2), 66-77. Thomas Telford Ltd.

Visschers, V. H., Wickli, N., \& Siegrist, M. (2016). Sorting out food waste behaviour: A survey on the motivators and barriers of self-reported amounts of food waste in households. Journal of Environmental Psychology, 45, 66-78.

Xue, L., Liu, G., Parfitt, J., Liu, X., Van Herpen, E., Stenmarck, Å., O-connor, C., Östergren, K., \& Cheng, S. (2017). Missing food, missing data? A critical review of global food losses and food waste data. Environmental Science \& Technology, 51(12), 66186633. 